\title{
LA DUCTILIDAD DE LOS DERECHOS HUMANOS
}

\author{
MANUEL ESTUARDOLUJÁNTÚPEZ* \\ "El secreto de la paz está en el respeto de \\ los Derechos Humanos." \\ San Juan Pablo II
}

\begin{abstract}
Resumen
El vertiginoso avance del tiempo, la tecnología y la comunicación masiva en las redes informáticas, nos obliga a reconocer que el conocimiento es expansivo y cada vez más universal. Los Derechos Humanos, más allá de las diferencias que podamos tener sobre sus notas características, su genética e incluso sus efectos; y a diferencia de las legislaciones locales que tienen cada vez más a especializarse y volver exhaustiva y totalmente delimitada su competencia, aquéllos se convierten cada vez más en razones fundantes del Sistema jurídico provocando validez a los actos, a los procesos y a los efectos que aquellos causan, solo si se les entiende dúctiles, es decir, capaces de llenarse de contenido en cada caso.
\end{abstract}

Palabras clave: Derechos humanos, derecho dúctil, principios, legitimidad, neoconstitucionalismo.

\begin{abstract}
The rapid advancement of time, technology and mass communication in computer networks, forces us to recognize that knowledge is expanding and increasingly universal. Human Rights, beyond the differences we may have about their characteristic features, and even genetic effects; unlike local laws which have increasingly specialized and comprehensive and fully enclosed back competence, those are converted each again in founding reasons of legal system causing validity to acts, processes and effects than those caused those, only if they understand ductile, that is, able to be filled with content in each case.
\end{abstract}

Keywords: Human rights, ductility law, principles, legitimacy, neoconstitucionalism.

* Juez superior titular y jefe de la Oficina Desconcentrada de Control de la Magistratura de la Corte Superior de Justicia de La Libertad, doctor en Derecho, doctor en Filosofía del Derecho y doctor en Administración de la Educación y maestro en Derecho Constitucional y Administrativo, docente universitario de postgrado; autor de libros: "El Razonamiento Judicial" (2005) Lima: Gaceta Jurídica; “Filosofía del Derecho"; "El positivismo jurídico” (2005) Buenos Aires: Ediciones jurídicas argentinas; "Diccionario penal y procesal penal” (2013) Lima: Gaceta Jurídica. 


\section{Sumario}

1.- Introducción. 2.- La teoría del conflicto. 3.- La teoría de las expectativas sociales. 4.- El derecho dúctil y el neoconstitucionalismo. 5.- El imperativo categórico. 6.- La casuística peruana. 7.- Conclusión. 8.- Bibliográfia.

\section{Introducción}

El gran maestro argentino Germán Bidart Campos sostenía en vida que los Convenios y Tratados internacionales sobre Derechos Humanos forman un sistema normativo anterior y superior incluso al sistema normativo constitucional de cada Estado, lo cual por cierto, no es solo una afirmación histórica. La Constitución Política del Perú de 1979 contenía una norma explícita de ese contenido en el artículo $105^{\circ 1}$. La Constitución Política actual tomó otro camino, no una regulación explícita sino una implícita. Y aunque existe opiniones contrarias, el profesor César Landa Arroyo ${ }^{2}$ ha sostenido la hipótesis que compartimos que no es necesaria tal redacción, pues la naturaleza de los Derechos Humanos impone un reconocimiento per se.

Son razones eminentes, sostiene el profesor Joaquín Jiménez fundados en la dignidad humana ${ }^{3}$, que incluso diría yo, si existiera una constitución obligatoria e ineludible, bajo la tesis kelseniana - que elimine los Derechos en el texto constitucional o más aún, que prohíba su imperio, aún en ese extremo los Derechos Humanos valdrían, pues así como se han acortado distancias por la tecnología de redes, así la humanidad ha empezado a generar un sistema de libertades cuyo ejercicio democratizado en el internet nos obliga a admitir que el progreso ha evidenciado que los Derechos Humanos o mejor dicho los Derechos de la humanidad son un conjunto de máximas que sobrepasan los Estados y los pueblos, e incluso las diferencias de persona a persona, y desconocerlos solo es una cuestión que poco a poco desaparecerá, por la eliminación de las fronteras, por ahora borradas cibernéticamente, a pasos de gigante las del mercado, pronto serán las de los derechos civiles y tal vez, no tan lejos, todo lo demás.

1 Los preceptos contenidos en los tratados relativos a derechos humanos, tienen jerarquía constitucional. No pueden ser modificados sino por el procedimiento que rige para la reforma de la Constitución.

2 LANDA ARROYO, César (2002) La aplicación de los Tratados internacionales en el Derecho interno y la Corte Interamericana de Derechos Humanos, México DF: UNAM, 319 a 347.

3 JiMÉNEZ SÁNCHEZ, Joaquín (1998) La fundamentación de los derechos humanos. Los derechos humanos como derechos morales, España - Granada: Cuadernos Electrónicos de Filosofía del Derecho. núm. 1, UGR. 
Así pues, incluso sin admitir que la finalidad de la Convención Americana de Derechos Humanos o Pacto de San José de Costa Rica, a guisa el primer Tratado sobre Derechos aprobado en el hemisferio; es la de reconocer la existencia de un cúmulo de libertades y derechos anteriores y superiores al Estado (Artículo $1^{\circ}$ ). La sola existencia del Pacto es la prueba más tangible que la humanidad desde hace buen rato ha iniciado una contraofensiva a la barbarie, a la violencia, al abuso o a cualquier forma de degradación del humano como digno.

Como prueba de ello, el Perú aprobó la Convención mediante Decreto Ley N ${ }^{0}$ 22231, ello significa que hasta un gobierno militar peruano tuvo que aceptar la valencia del contenido de Derechos. $Y$ aunque existen muchas explicaciones a este fenómeno, la que más me gusta es que somos imagen de Dios, y como decía San Agustín nuestro corazón estará inquieto hasta que no descanse en él, de cuya imagen existimos.

La ductilidad de los Derechos Humanos no ha sido sino su más reciente presentación, y aunque no la única, genera desde hace un buen rato, la posibilidad de convivencia y gobernabilidad dentro de las diferencias, si se quiere en palabras simples: lo mínimo que nos hace iguales a todos.

\section{La teoría del conflicto}

Hoy en día es casi pacífica la doctrina que entiende que la Ley Fundamental de un país, o la Constitución es no solo una norma política sino también una norma jurídica, y más aún una norma abierta; y por ello, dúctil. Tal reconocimiento proviene hoy, tanto de la Academia como de la jurisprudencia.

Así por ejemplo lo contiene la Sentencia del Expediente No. 05854-2005PA/TC - PIURA, PRECEDENTE VINCULANTE, Caso Pedro Andrés Lizana Puelles, del 8 de noviembre de 2005, "El Estado Constitucional de Derecho supone, entre otros cosas, abandonar lo tesis según la cual la Constitución no era más que una mera norma política, esto es, una norma carente de contenido jurídico vinculante y compuesta únicamente por una serie de disposiciones orientadoras de la labor de los poderes públicos, para consolidar la doctrina conforme a la cual la Constitución es también una Norma jurídica, es decir, una norma con contenido dispositivo capaz de vincular a todo poder (público o privado) y a la sociedad en su conjunto. (...) Conforme a lo anteriormente expuesto, afirmar que existen actos de alguna entidad estatal cuya validez constitucional no puede ser objeto de control constitucional, supone sostener, con el mismo énfasis, que en tales ámbitos la Constitución ha perdido su condición de norma jurídica, para volver a ser una mera carta política referencial, incapaz de vincular al poder." 
En comunión como lo reconoce la doctrina de fines del siglo $X X$, en que un fenómeno recurrente aparece entre varios pensadores de la Europa continental: empezaron a ver a la Constitución, no solo "como el programa de un proyecto determinado de vida en común sino más bien como la garantía de legitimidad para realizar las condiciones de la vida en común"4.

Pero si esta ecuación es en este día casi perfecta, cómo es posible que en el Perú, varias instituciones constitucionales básicas no sean aceptadas en la dimensión democrática que se requiere: El poder es utilizado con fines particulares, por lo que se convierte en abuso; las decisiones judiciales no se respetan decayendo su eficacia constitucional y acrecentando la desconfianza social en la administración de justicia; el respeto democrático de las decisiones es casi ilusión; la autoridad no es respetada por lo que permite el decaimiento de las instituciones y la anomía social. Y podríamos seguir con un largo etcétera, por lo que es necesario, volver al comienzo de la sociedad.

\section{La teoría de las expectativas sociales}

Si hay un misterio que a cualquier abogado le debe sorprender más, ese es el fenómeno social. Un abogado debe trabajar para mantener el orden social establecido mediante la realización de la justicia en defensa del derecho y por sobre todo del ejercicio libertario del derecho que le es inherente a todo ser humano, por el solo hecho de serlo. Entonces si comprende bien su vocación significa que el abogado o la abogada, si quiere cumplir su trabajo a cabalidad, deben hacer que prime la libertad individual aunque suponga el sacrificio de la convivencia social que precisamente le impone una barrera a la libertad que defiende. Algo así como "Fiat iustitia, pereat mundus" o sea, que se haga justicia aunque perezca el mundo.

La vida en sociedad implica muchas contradicciones. El primer signo de contradicción es que los hombres buscan ser felices y al mismo tiempo necesitan ser libres pero ocurre que la convivencia social requiere para supervivir precisamente la limitación a la libertad y muchas veces el sacrificio de felicidades menores en procura de una mayor felicidad. Es decir, si queremos vivir en sociedad debemos aceptar renunciar a la libertad y a la felicidad plena. O si se prefiere, dicho más románticamente, debemos renunciar a la libertad para ser felices. Pero ¿cuál es la medida de la renuncia que se exige?

4 ZAGREBELSKY, Gustavo (2008). El derecho dúctil, traducción Marina Gascón, 5a. ed., Madrid: Trotta, pp. 5 y siguientes. 
Jean Jacobo Rousseau (ROUSSEAU, 1999, pp. 4 a 5) sostenía que el hombre renuncia a su libertad natural con la que nace a favor del Estado y este la devuelve convertida en libertad civil, que por la voluntad general - una especie de demiurgo que todo lo hace posible - resulta ser idéntica a la libertad natural de la cual se renuncia y por ello el pacto social es perfecto.

Y aunque reconozco que la religión civil es una de las explicaciones más aceptadas por siglos, me resulta difíil de comprender que el acto más sublime del hombre en cuanto tal, aun y especialmente contando con su miserable egoísmo, sea un simple acto de dirección exterior. Y me gustaría colocar las cosas en proporción. Es decir, permítanme encontrar una respuesta más lógica para explicar el acto de renuncia, pues tiene que haber algo más que admitir una fuerza ultraterrena - y por cierto no divina, ya que no se trata solo de un teísmo - llamada voluntad general que nos hace renunciar al ejercicio de la libertad máxima.

Y digo máxima, porque la libertad sin límites es imposible ${ }^{5}$. Veamos, existe una limitación física pues nadie podría hacer aquello que no puede, por ejemplo atravesar una pared, entonces el ejercicio de su libertad se encuentra limitado por la naturaleza. También está limitado por la voluntad, puesto que ninguna persona puede hacer dos cosas incompatibles entre sí, por ejemplo si quisiera viajar a dos lugares distantes con un presupuesto que solo le alcanza para uno, tendrá que elegir, y ello supone que el ejercicio de su libertad se limita por las posibilidades que su voluntad le imponga, incluso en el extremo que la elección sea un mero capricho. Así que la libertad puede ser ejercitada máximamente pero no ilimitadamente.

Y volviendo a la pregunta ¿qué podría explicar que el hombre sacrifique su libertad que le es tan esencial solo por vivir en sociedad? Claro que las antípodas de la explicación podemos encontrar tanto la resignación como la inexorable persistencia del demiurgo. Sin embargo, ambas posiciones, precisamente por ser extremas poseen objeciones radicales.

Primero la resignación, significa que el hombre por su racionalidad ha llegado a la convicción que sus limitadas potencialidades no le permiten hacerlo todo y solo, pero tomando "mutatis muntandis" la crítica a la posición original o el velo

5 Jurídicamente hablando, el Tribunal Constitucional ha sostenido tal postura en diversas sentencias, por todas podemos citar como ejemplo el STC EXP. No. 00019-2005-PI/TC-LIMA, Caso prisión preventiva - Ley No. 28568 que modifica artículo $47^{\circ}$ del Código Penal, del 21 de julio de 2005, FJ. 12. (...) como es doctrina reiterada de este Colegiado, ningún derecho fundamental es ilimitado. 
de la ignorancia de John Rawls ${ }^{6}$ quien proponía que un Parlamento perfecto para una sociedad justa exigía que todos los representantes sociales sean en cantidad igual por cada colectivo, a lo que se requiere como segundo elemento que todos los representantes pierdan la memoria, así ninguno podría tomar posturas absolutistas. Pero ¿qué si hay un terco, alguien que se las juegue todas por una decisión fascista? $\mathrm{Y}$ ¿qué si todos fuesen tercos? El velo de la ignorancia reposa en que todos los desmemoriados, cuando deban proponer alguna postura al no saber a qué colectivo representa solo propondría medidas que favorezcan a todos o a muchos, o al menos evitaría propuestas que sean discriminatorias o sectarias, pero con un terco o con todos tercos, a cualquiera no le importaría ser el único que sufra con una medida fascista, igual la aprobaría. Lo mismo pasaría con la resignación, ya que tal posición supone que el humano ha concluido que hacerlo todo solo supone un inmenso esfuerzo que admite limitar su libertad con la finalidad que viviendo en sociedad todo sea más fácil, entonces, si alguien en alguna parte propusiera no resignarse, y liberarse aunque el precio fuese llenarse de Robinsones Crusoe, bastaría que uno solo se lo proponga en serio, para que tal acción se propague mundialmente, pero ocurre que la historia está llena de insurrecciones, es más la mayoría de ellas han concluido en emancipación: digamos la máxima expresión que conocemos de libertad porque concluye en la independencia de los pueblos colonizados, pero solo para fundar una nueva sociedad, con mayor libertad, pero igual con miles o millones de sujetos resignados, lo cual no tiene lógica, en especial si pretendemos que la solución a la sujeción y a la convivencia social sea un acto de racionalidad que es la resignación. Por lo tanto por reductio ab adsurdum la resignación no puede ser la respuesta.

Luego la inexorable persistencia del demiurgo. Con la misma convicción en la imposible existencia del universo sin Dios. También considero que un sistema de perfección creado es imposible si dotas al hombre de libertad solo para que renuncie a ella, si para Dios no fuera indispensable respetar tal libertad. Por lo tanto considerar que los hombres vivimos en sociedad, porque habiendo sido hechos para ello, por la voluntad del demiurgo, resulta inútil que no tenga la misma potencia como para hacerlos dóciles, sino que son hechos con libertad a la cual renuncian a favor del Estado, que les devuelve la misma libertad pero convertida en civilidad o ciudadanía que por voluntad del demiurgo es idéntica a la libertad natural con la que los hombres nacen. Entonces, el demiurgo mismo, atenta contra la navaja de Ockam: esentia non sunt

${ }^{6}$ RAWLS, John. La teoría de la justicia, 6ta. Reimpresión, México: Fondo de Cultura Económica, 2006, pp. 171 a 176. 
multiplicanda praeter necessitatem. ${ }^{7}$ Pues si aceptamos la existencia de un demiurgo que modela la sociedad, aunque le llamemos como Rousseau: voluntad general, resulta absurdo que haya dado libertad al hombre si lo iba a ser social, así que aunque es algo milagroso - y a priori no lo descarto - no resulta coherente. Puesto que si lo podía hacer social, a pesar de la libertad, no hubiera sido más simple hacerlo sin libertad. Por lo tanto, también por reducción al absurdo, esta respuesta tampoco es posible de admitir.

Descartadas las antípodas cualquier respuesta es posible entre ellas, no pretendo agotar estas páginas desarrollando las demás posibilidades. Así que abreviemos: una respuesta posible es la teoría de las expectativas sociales.

La hipótesis de las expectativas sociales nace hace mucho, no exactamente cómo se las explicaré pero encontramos mucho sobre ello en la psicología social $^{8}$ que define la expectativa social de la siguiente forma:

"En todos los grupos sociales, la tradición cultural asigna normas de comportamiento a las que espera que se adapten sus miembros. Generalmente implíitas, estas normas imponen códigos de conducta que no es fácil rehuir, por ejemplo, el que una mujer deba tener gestos delicados o que si la familia de una persona es adinerada, entonces esa persona debe vivir en una casa lujosa.

Lo que empieza como una imitación por parte de los hijos de lo que hacen sus padres se convierte en su propio modo de ser. Esto quiere decir que las personas adquieren un rol a partir de los demás, y acaban creyéndolo propio. Se puede decir entonces, que somos lo que los demás esperan que seamos."

Partiendo de estos conocimientos mi propuesta nace en el milagro del primer venado. Pero antes me gustaría exponer la hipótesis como la entiendo. Los humanos son plena y totalmente libres, es decir los humanos pueden de hecho hacer todo aquello posible (dentro de los límites físicos y volitivos) y por ello pueden incluso dejar a un lado su libertad. Pero obviamente, debe existir una explicación igualmente racional para que los humanos que pueden ser libres, quieran dejar de serlo. Una renuncia tal, solo puede ser explicada por un bien mayor. Y ese bien mayor es la felicidad. Es decir, la fuerte convicción que viviendo en sociedad será posible alcanzar la máxima felicidad posible, incluso admitiendo que la felicidad plena - terrenalmente hablando es imposible - la máxima felicidad incumbe todas aquellas expectativas que su libertad le

\footnotetext{
Guillermo deOckam sostenía que lo esencial no debe multiplicarse más allá de lo necesario.

8 IGLESIAS, Raúl, (2015). "El poder de las expectativas sociales: El efecto Pigmalión", en Curso de Piscología Social, pp. 5 a siguientes, consultado el 06 de febrero de 2016 en http://www.psicologoescolar.com/ORIENTACIONES_GRATIS/114_lo_que_el_efecto_pigmal ion_nos_ensena.htm
} 
permitiría alcanzar, pero que en soledad o mejor aún con todos pretendiendo alcanzar la misma libertad, resulta inalcanzable. Por lo tanto reconociendo que todos tenemos las mismas expectativas, el humano racionalmente concluye lógicamente que renunciando a parte de su libertad que espera todos renuncien, permitiría que todos alcancen las expectativas deseadas, que solo pueden existir gracias a la mutua renuncia, generando una expectativa común que se conoce como expectativa social.

Para alcanzar este estado de eficiencia, requiere por cierto un acto de racionalidad, pero al mismo tiempo un acto de esperanza. La razón nos permite concluir que somos limitados que la libertad sin límite es imposible. Pero también nos permite inferir que todos somos igualmente limitados e igualmente expectantes de una libertad máxima. Esperamos que siendo todos iguales, en un punto determinado de ensayo y error los humanos podemos concluir igualmente en la misma respuesta: cedo para ganar. A partir de ese mutuo reconocimiento de la limitación y de la imposibilidad de la máxima libertad, es que logramos fundar el Estado, renunciando al poder absoluto. Por supuesto, este acto de generosidad que expresa la máxima humildad del humano, no puede ser un acto casual y menos un movimiento dirigido, porque entonces deja de ser humano.

Para llegar a alcanzarlo necesitamos remontarnos muchas centurias atrás al comienzo de la humanidad, no importa cuál sea la filosofía que domine tu vida, si quieres puedes pensar que evolucionamos al punto que fue el Cromagnonense el que venció en la cadena evolutiva, si prefieres que vinimos en alguna criogénica roca del espacio exterior, o sino acompáñame en admitir que solo un ser perfecto, vital, motor, esencia nos causó: Dios.

No quisiera discutir aquí como llegamos, ese es un tema más largo y necesita más vida para desarrollarlo. Partamos de lo que coincidimos, en un momento determinado la humanidad empezó. Pero ¿qué nos hizo renunciar al poder absoluto? Por cierto no ha sido una renuncia lineal, aún existe la esclavitud, la trata de personas, la soberbia, la pedantería, el chovinismo, la discriminación, la canallada de actuar mal y encima increparle al que está de la otra orilla y muchas otras enfermedades del alma que nos recuerdan que la renuncia primitiva debe ser actualizada, y requiere un acto de sublime armonía y por cierto un acto de agudeza intelectual algo así como lo que decía el psicoterapeuta argentino Jorge Bucay "El verdadero amor no es otra cosa que el deseo inevitable de ayudar al otro para que sea quien es". 
Para alcanzar este nivel de grandeza, necesitamos una dosis de imaginación y una doble dosis de lógica. Cuando el primer humano estuvo en la tierra, probablemente con otros humanos, es casi seguro que el primer apetito que haya tenido sea hambre. Entonces, no importa mucho como lo haya logrado, aunque colabora mucha en el razonamiento pensar que utilizó su intelecto para cazar. En ese momento mediados del Pleistoceno del cuaternario estaba a punto de extinguirse la megafauna del Pleistoceno, digamos para no ser exagerados que el ser humano logra cazar un becerro de venado. Para ponerlo en perspectiva antes de extinguirse - precisamente a causa nuestra - y escojo un cérvido, para no mencionar al Mamut que sería más difícil de cazar. Bien, antes de su extinción el Megaloceros Giganteus o si prefieren alce irlandés, media en promedio 3 metros de largo y 2,5 metros de ancho, pesaba 750 kilogramos, digamos que un hombre promedio parado podía acariciarle la panza.

En aquel entonces la comida no se cocía, por lo que la digestión de carne cruda era más lenta, así que si con buen apetito podemos pensar que comemos un kilo de carne cocida, si solo estuviera asada al fuego, tal vez no lleguemos ni a 500 gramos, en un día. Ahora pensemos en comer algo más de media tonelada, incluso sin los huesos ni el cuero, resulta imposible pensar que un solo humano haya podido acabar con un becerro de ciervo gigante.

Así que el cazador solitario tiene una de dos opciones, saciar su hambre lo más que puede y luego abandonar el resto de la presa o quedarse con la comida para consumirla de a pocos. La primera respuesta puede ser si pensamos que existe abundancia, pero ocurre que las glaciaciones están acabando con la megafauna y abandonar una presa no sería la respuesta más inteligente.

Pero quedarse con ella implica varias problemas, primero están los otros cazadores, y en ese tiempo no había muchos sitios para ocultar una presa tan grande, sin mencionar cómo trasladarla, segundo están los otros predadores naturales que al olor de la sangre llegarían pronto y por último está la capacidad de respuesta del hombre haciendo digestión, porque al igual que ahora tendría somnolencia. Es imposible pensar que el humano se quedará despierto y alerta todo el tiempo para cuidar su presa. Entonces, puede luchar con los otros cazadores con poco éxito en la batalla, o negociar una salida pacífica pero más eficiente. Compartir la presa, a cambio de poder (Autoridad), a cambio de una recompensa alternativa (Trueque), a cambio de organización (distribución de la riqueza). Entonces compartir "a cambio de", permitió el nacimiento de la humanidad, si se prefiere de la sociedad humana, en ese acto de inteligencia de reconocer que la limitación solitaria no le permitiría la 
sobrevivencia, pero la convivencia sí le permitiría la tranquilidad. El humano aprendió que la renuncia no tiene que ser entitativamente nociva sino que puede ser utilizada para alcanzar la seguridad que su limitada humanidad no le permitía. Ese primer venado le enseñó que todos tenemos la misma expectativa vital, pero que si todos la pretendemos actualizar, todos perdemos, solo renunciando todos a todo, podemos alcanzar todos colmar la misma expectativa que compartimos. Entonces la sociedad nace de un acto de esperanza. Pues todos esperamos que los demás se comporten de la misma manera que uno y que todos concluyan que la única manera de ser lo más felices posible, es renunciando a ser ilimitadamente libres, que por cierto, ni en el estado natural lo podríamos ser.

Y para no contradecir del todo al eminente Aristóteles y su "homo zoopolitikos". Incluso admitiendo que el primer paso gregario es natural. La persistencia en lo gregario, es decir el constante renovar el pacto social, tiene que ser un acto racional; pues, resulta imposible admitir que un ser pensante que recibe constantes mensajes para alejarse de la sociedad (inseguridad, discriminación, egoísmo, envidia, frescura, etc.) siga siendo gregario a pesar de todo. La única explicación lógica es que la caja de Pandora aún permanezca con el último bien no liberado por su curiosidad ${ }^{9}$ (HESIODO, 2003, 56 a 69) encerrado por la misericordia divina: La esperanza de alcanzar la expectativa de felicidad.

La suma de todas estas expectativas individuales genera las expectativas sociales, lo que finalmente nos permite ser Nación, al identificar que cada humano que le rodea, en especial los más cercanos comparten la misma expectativa. Entonces, la sociedad se revitaliza y nace cada día nueva, con la actualización de ese reconocimiento racional, y por ello si queremos seguir existiendo como grupo social organizado (o sea como Nación) lo que debe protegerse es la consecución real de la expectativa, y para ello, la sociedad ha inventado los roles sociales que van permitiendo alcanzar expectativas comunes que a la postre permiten la expectativa de felicidad.

9 Según el mito griego, Zeus hizo a Pandora como compañía para los hombres y en compasión por el castigo de la partición al haber sido cómplices de Prometeo para robar el fuego de Hefestio. Todos los dioses le dieron alguna gracia a Pandora, pero Hefestio que seguía molesto le dio la mentira y la falacea. Zeus entonces le dio una caja de cedro en la cual guardó todos los bienes y gracias y también todos los males y desventuras, y la dejo en la tierra con los hombres, con la expresa indicación que no abriera la caja por ningún motivo. Por supuesto, como una invitación, fue lo primero que hizo, y por eso todos los bienes y todos los males le ocurren a los hombres, pero justo antes que la caja quede vacía Zeus la cerró, dejando adentro al último bien: La esperanza. 
Entonces, y no por venganza, se explica que toda conducta contraria a la expectativa (independiente del móvil) sea sancionable. El móvil intencional agrava la sanción pero su ausencia no la elimina. Y en esa proporción también aparece el grado de sanción que puede ser civil, religioso, administrativo, social, política o penal.

Es inevitable consentir que el Tribuno alemán Gerhard Leibholz tenía razón cuando dijo: "La libertad genera inevitablemente desigualdad. Cuanto más libres son los hombres, tanto más desiguales" (LIEBHOLZ, 1963, p.25) Por ello, con mayor fuerza afirmo que la convivencia social no puede ser sino un acto racional, por el cual se renuncia a la máxima libertad con el fin de alcanzar la expectativa de felicidad que todos compartimos. Aunque claro siendo un acto de esperanza, más que de fe racional como lo pretendía Rousseau, no existe la seguridad plena de su realización, sin embargo, está inversamente relacionada con aquella, mientras más renuncien al máximo ejercicio de libertad, más humanos potencialmente felices existen.

Este acto de racionalidad o mejor dicho - parafraseando al Profesor Joaquín Jiménez - este acto de razonabilidad pasa por cuatro estaciones, según el menester de aspiración que el humano alcance, y valga decir ello, no todos alcanzan el último grado de madurez pues está relacionado con la madurez emocional y no con la madurez racional. Vinculado esencialmente como lo sostenía el eminente Carlos Cossío en su "teoría egológica" al desarrollo del "yo". El primer descubrimiento del hombre es precisamente "su yo", es la madurez del niño, cuando nos descubrimos independientes del mundo, por eso es "mi mamá", "mi pelota", "mi perro", "mi casa". Aparece la primera expectativa que podemos llamar la expectativa social primordial en la que nos conducimos a vivir juntos como nación. Esta expectativa la comparten todos los colectivos primarios: regionalismos, fascismo, terrorismo, crimen organizado, etc. en este entorno la máxima aspiración del hombre es cumplir un rol social primordial consistente en vivir en paz, defender al grupo y mantener la cohesión, no se requiere aspirar demasiado, más que a conseguir las condiciones básicas para la subsistencia, admitiendo la mínima renuncia del ejercicio libertario que es la sujeción a la autoridad, por cierto, mientras esta mantenga la hegemonía del poder. Es precisamente en esta estación que aparece el Estatuto social, que es el Pacto social original: vivir en grupo, pues el grupo me permite la subsistencia, y por tanto, el proyecto vital se reduce a sobrevivir cada día.

Dígase de paso que la idea del Estatuto social, en contrario del Estatuto natural. Ese modo angélico de perfección y armonía en que todos - sin la carga de la 
concupiscencia - lo podíamos todo porque lo teníamos todo, sea solo un punto escatológico de referencia. El estatuto social es el conjunto de reglas, prerrogativas, derechos y obligaciones que permiten la realización binaria, tanto del ser humano en su aspiración primordial como de la sociedad en su génesis. Como todo estatuto, marca los accesos y salidas, así como las sanciones por el incumplimiento de las reglas, fijando los límites para todos los que deben compartir dicho Estatuto. Así con mayores condiciones el Estatuto social se eleva, con mayores cargas, hasta consolidar el Estatuto funcional, como categoría o condición de actuación pública que recibe el personal al servicio del Estado, (Funcionario o servidor cualquiera sea su vínculo contractual) con la finalidad que su manifestación se convierta en voluntad pública, expresa, ficta o manifiesta. El estatuto funcional lo compone el acceso, los derechos, deberes, responsabilidades e impedimentos a que están sujetos, así como el personal que se encuentra excluido del estatuto: los trabajadores de empresas del estado y sociedades mixtas.

Las otras dos estaciones de la evolución sicológica del humano radican en el descubrimiento del "otro", involucra la madurez del adolescente, que puede compararse a compartir el pan. Mientras en el primer descubrimiento "el yo" en que el pan se lo come enteramente el descubridor porque es "su pan". En el descubrimiento del "otro" comparte el pan con él, es posible que inicialmente sea en un 90/10 o tal vez en el mejor de los casos 70/30 hasta alcanzar el Pareto eficiente de 50/50, que supone ya una madurez juvenil. En esta estación existen dos niveles, primero la expectativa social básica o general en la que fundamos la sociedad que crece como unidad familiar, luego institucional, y por último, política; la máxima aspiración en este nivel es cumplir el rol político básico realizando la expectativa de fundar una familia, transitar, educarse, expresarse, sufragar, por ello en este nivel se engendra la ciudadanía como parte del Estatuto civil, que desde luego comienza desde la familia, en donde la ciudadanía familiar se alcanza cuando los hijos son considerados para las decisiones básicas: dónde ir de viaje, dónde vivir, etc. hasta que la fuerza de la convivencia permite la aparición del grupo idiosincrático que evoluciona finalmente en el Estado, que posee el patrimonio exclusivo y excluyente del poder.

Luego aparece la expectativa social especial en la que no solo nos contentamos con vivir en grupo para lograr el 70\% del pan, sino que la madurez racional impele a considerar que vivir juntos es la única manera de ser más feliz, por lo que se busca alcanzar la plenitud del desarrollo en el grupo, en este nivel superior cumplimos el rol social especial consistente en realizar una función social 
colectiva con fines de riqueza: Trabajar, comerciar, transportar, fundar empresa, ya no solo el proyecto de vida consiste en vivir, sino en tener una vida mejor para lo cual es indispensable elemento: la riqueza, para lograrlo, el ejercicio de la libertad se renuncia a favor del imperio de la voluntad del otro, que para ser perfecta, tendría que ser por el bien del renunciante. Así por ejemplo, el pasajero renuncia a su libertad ambulatoria al subir al taxi, al bus, a la combi, a la mototaxi, pues es el conductor el que lleva al pasajero por caminos que no define, incluso poniendo en riesgo su seguridad si es más veloz, o se trata de un conductor con muchas infracciones, riesgos que el pasajero se permite porque es más rápido el motorizado que el camino pedestre. O el comensal renuncia al ejercicio libérrimo de su salud al ingresar a un restaurant o un bar, es el chef quien elige los ingredientes, aunque se pone en riesgo la salud, pues la despensa la elige el comerciante, mientras el comensal no tiene dominio de la frescura de los comestibles, o la salubridad de la cocina, menos del aseo de los utensilios. En ambos ejemplos, existe el riesgo vital, pero se admite a cambio de la riqueza, porque esta nos permite una mejor vida que solo la manutención. En contraprestación la sociedad organizada exige el tributo para el sostenimiento del Estado, apareciendo el Estatuto público administrativo, en el que el ciudadano del Estatuto civil posee obligaciones y límites para el ejercicio de su libertad como sujeto de la Administración Pública.

En el grado más alto, del descubrimiento humano en su evolución sicológica aparece "la humanidad" y para seguir con la metáfora del pan en la madurez del adulto, el humano llega a la capacidad de desprenderse totalmente del pan con la finalidad que los demás puedan comer. Este grado de generosidad o desprendimiento, solo entendible desde una visión Paulista del amor, comparable para no poner a Nuestro Señor Jesucristo, a la longanimidad, altitud, profundidad o amplitud del amor de madre. En este último nivel la expectativa social especial exige al humano contribuir al desarrollo grupal, realizando el rol político especial, es decir, la realización de la vocación pública, el grado de nobleza de las profesiones de servicio, en el que ocupa su centro la función pública con fines de satisfacer las necesidades de los demás, bajo la prerrogativa de concreción del bienestar de todos, en que se manifiestan los actos de Educar, gobernar, curar, servir. La aparición del Estatuto funcional es no solo la máxima expresión de la renuncia, también es la máxima aspiración de la expectativa, pues el humano espera una calidad de vida mayor. Aunque por cierto, como está directamente vinculada a la madurez emocional no siempre es fácil alcanzar la realización de esta última etapa de evolución. 
Bajo esta comprensión final los Derechos Humanos son casi indispensables, sin embargo exige un largo camino por recorrer, en especial si pretendemos aplicarlos armónicamente, ello supone reconocer su ductilidad.

\section{El derecho dúctil y el neoconstitucionalismo}

Para el profesor italiano Gustavo Zagrebelsky ${ }^{10}$ la mejor característica que describe hoy el Derecho en especial el Constitucional es su "ductilidad", pues facilita los fines de unidad e integridad al posibilitar la coexistencia de valores y principios diferentes en un mismo sistema jurídico. La ductilidad es la característica del Derecho que permite adecuar la norma jurídica a cada situación concreta, hallando la interpretación que fuera más compatible con la optimización de los derechos de todos, de tal manera que consigue evitar que la Constitución se haga incompatible con la base material pluralista de nuestras sociedades esencialmente democráticas, fijando los presupuestos de convivencia, los principios sustanciales de la vida en común y las reglas del ejercicio de poder.

Hablamos entonces de un Constitucionalismo de principios, más que un Constitucionalismo descriptivo o un Constitucionalismo reglado un auténtico "Diritto mitte"11 o mejor un Derecho pluralista que está en constante hacerse. Ahora bien, hablar de un Constitucionalismo de principios, importa admitir que tras el legalismo jurídico y la codificación del decimonónico en el Estado de Derecho, a la que le acompañó el Constitucionalismo del vigésimo en el Estado Constitucional de Derecho; le sigue el "no positivismo principista" del siglo XXI en lo que llamaremos el Estado nomoárquico del Derecho en una visión neoconstitucionalista.

La doctrina de la Europa continental conocida como neo constitucionalismo que posee ahora varios defensores, y que tiene como su protofundador yo diría a Carl Schmitt con su "Nomos de la tierra"12, nace como la necesidad básica de los pueblos europeos por unificarse en una nación y de alguna manera evitar el desangramiento fratricida alimentado durante siglos por la codicia de los

10 ZAGREBELSKY, Gustavo (2008). El derecho dúctil, traducción Marina Gascón, 5a. ed., Madrid: Editorial Trotta, pp. 9 a 14,122 a 124.

11 La doctrina del Diritto mitte nace en Italia que considera al Derecho no como un dato (hecho) sino como un camino o un proyecto (por hacerse) donde convergen innumerables exigencias planteadas por principios a veces en las antípodas de la reflexión incluso con apariencia contradictoria, solo así, en una diferencia tan grande de nacionalidades permite la convivencia de una misma comunidad estatal.

12 SCHMTT, Carl (2003). El nomos de la tierra, en el Derecho de Gentes del Ius Publicum Europeum, Granada: Comares. 
gobernantes o mejor aún de los poderosos, y eliminar el látigo de la guerra, en especial de las dos últimas guerras mundiales. Pero cómo puede ser posible, siendo Europa tan diversa con diferentes culturas, lenguas y razas - entiéndase pueblos. La respuesta próxima nace de la pluma de Luis Prieto Sanchís, Luigi Ferrajoli, Mauro Barberis, Mauro Cappelletti, Pietro Comanducci, "haciendo que la norma jurídica sea interpretada antes de volverse condicionante y por tanto antes de aplicarse establecer las posibles consecuencias, eligiendo aquella que mejor proteja los Derechos Humanos, y si varios en juego aquel que en el caso concreto deba prevalecer"; ello nos obliga a no descartar ningún postulado o principio a priori, así como a tolerar las diferencias que pueden convivir mientras respeten el imperativo categórico. Por cierto no es una doctrina fácil de admitir, menos aún en una cultura ultra positivista como la nuestra.

El neoconstitucionalismo posee algunos principios básicos: el alcance privilegiado y prevalente de los Derechos Humanos, la omnipresencia de los Derechos Humanos, la interpretación de la ley y la conversión de esta en condicionante de conducta a partir del constructivismo. Me gustaría solo enfatizar esto último, ya que todo los demás parece más obvio: en cualquier Estado existe un legislador o si se prefiere una fuente de disposiciones jurídicas, no obstante cualquiera sea su denominación (ley, acuerdo social, sentencia, dogmática, costumbre, jurisprudencia) todas ellas son finalmente informaciones, cuyo destinatario elige si las considera significativas o no, como en cualquier acto comunicativo ${ }^{13}$ por lo tanto para que alcance el carácter de condicionante de la conducta no es suficiente con que estén promulgadas sino que el destinatario tiene que aceptar su validez y mejor aún actuar conforme a ellas, solo entonces hablamos de la existencia de norma jurídica, mientras ello no ocurre podrá ser solo una fuente de norma jurídica, una referencia, una sugerencia de actuación, una sugerencia legal de actuación, pero no un imperativo.

Bajo esta comprensión de Derechos Humanos fundantes y privilegiados, además de plurales, nos obliga a reconocer en principio su naturaleza principista o nomoárquica, tal como lo dice Robert Alexy "los derechos humanos tienen naturaleza de principios y los principios son mandatos de optimización que en su efectivo cumplimiento poseen grados de cumplimiento los cuales dependen de las posibilidades reales y jurídicas que evidencian su concreta existencia"14. Pero al

13 HABERMAS, Jürgen (1987). La teoría de la acción comunicativa, Madrid: Taurus; (2002) Verdad y justificación, Madrid: Trotta.

14 ALEXY, Robert (2002). Teoría de los derechos fundamentales, Madrid: Centro de Estudios Políticos y Constitucionales. 
mismo, tiempo en oposición a la doctrina alexyana del conflicto de principios o derechos, posee dos características en ellos y en los principios que los estructuran. Su dinamismo y la ausencia de jerarquía estática, ambas variables por cierto no son excluyentes sino convergentes entre sí. Así pues, abandonando la antigua tesis que los principios son estáticos con un contenido preestablecido en la Ley o mejor en la Constitución, y que poseen una jerarquía intrínseca consecuente, por ello bajo esta premisa es inevitable hablar de colisión de principios y por ende del obligado ejercicio de la ponderación. Sin embargo, entenderlos como dinámicos, la interpretación mejor tiene que ser "dúctil" es decir aquella que permita la pacífica existencia de todos los Derechos Humanos, aunque claro, el alcance de algunos puede ser privilegiado en algunos casos, mientras que en otros será recesivo, pero jamás se aniquilaría, como lo concebía el maestro argentino Germán Bidart Campos, (BIDART, 1989, pp. 365 a 372) en donde juegan un papel mediador los principios $^{15}$.

Tal como lo expuso el Profesor Karl Larenz ${ }^{16}$ “...no se trata de enunciados cualesquiera, sino de prescripciones que han de obedecerse, de pautas de juicio prescritas, brevemente: de normas. El legislador que promulga una ley, o más exactamente que pretende regular un determinado sector de vida por medio de normas, se deja guiar al respecto por ciertas intenciones reguladoras y por consideraciones de justicia o de oportunidad... al "aplicar" la norma se trata siempre de una valoración es algo que ciertamente no se manifiesta como el supuesto de hecho de la norma está formulado en conceptos fácticos libres de valoración, bajo los cuales puede ser "subsumido" el hecho enjuiciable mediante un procedimiento lógico. Un tal procedimiento requiere la comprobación... que todas las notas distintivas que forman el concepto han de encontrarse en el hecho enjuiciable. Si esta comprobación puede lograrse, entonces se sigue de ello, conforme a las reglas de la Lógica, que el hecho cae dentro del concepto...".

Entender a los Derechos Humanos como dinámicos, plásticos, dúctiles, es afirmar que los principios y los Derechos Humanos mismos poseen solo una referencia, un anclaje en la Constitución o en los Tratados que sobre esas materias se han escrito, pero en modo alguno los limita, al punto que ni siquiera deben estar por escrito para ser exigidos, como el caso del derecho a la verdad, al agua potable, a la ejecución de la sentencia, a la proscripción del

15 BIDART CAMPOS, German (1989). Teoría general de los Derechos Humanos, México D.F.: Universidad Nacional Autónoma de México.

16 LARENZ, Karl. (1994). Metodología de la Ciencia del Derecho, Barcelona: Editorial Ariel S.A., pp. 203205. 
estado de cosas inconstitucionales; bajo ese sino su contenido y su posición en el caso concreto, depende de éste, del contexto, de las condiciones de su ejecución; y si forman una jerarquía será casuística y esta eventual como en el modelo de Rudolf Stammler ${ }^{17}$.

\section{El imperativo categórico}

Ahora bien, la mayor objeción a este modo de pensamiento es la arbitrariedad, la inseguridad, la pérdida de la soberanía y el temor al capricho del Juez. Ya que no teniendo un contenido estático los Derechos Humanos, puede encontrar cualquier argumentación para justificar el abuso, la ilimitada discrecionalidad y hasta la inseguridad. Para contestar esta objeción, debemos partir del reconocimiento que tal postura posee un axioma falso, que es la pretensión ontológica del derecho, que es considerar que los Derechos humanos escritos generan limitación y seguridad.

En segundo lugar, es desconocer que la posición ontológica del Derecho es huérfana si no se afinca en el tomismo radical de la escolástica media, de la ley humana, escrita o positiva como reflejo de la ley divina o al menos de la ley natural. Posición que además resulta solo posible desde la revelación o el iluminismo casi diría panteísta. Pues para estar seguro que una determinante jurídica (digamos el Derecho Humano) es de tal manera y no de otra dogmática absolutista - se debe tener la absoluta certeza de la identidad del Derecho Humano definido con la Ley divina o al menos con la Ley natural, y ese conocimiento solo es propio de Dios. Me temo que tal certeza desde una postura laica o mejor dicho, desde una textura plenamente humana, piénsese por ejemplo del Derecho Humano a la legítima defensa, de radical oposición a la Ley divina del amor, donde el perdonar a los que te odian e incluso no levantar la mano contra quien te ofende, no tendría argumento defensivo alguno.

Los Derechos Humanos primordiales o los principios fundantes del Estado, son - y es bueno que así sea - conceptos jurídicos indeterminados: como la dignidad, la persona humana, o la no discriminación. Precisamente, su condición de validez omnicomprensiva radica que sean indeterminados. Precisamente como lo enfatiza Chaim Perelman ${ }^{18}$ si una ley pretende vocación universal debe ser general, de tal suerte que su longevidad está inversamente

\footnotetext{
17 STAMMLER, Rudolf (1970). Teoría del Derecho justo. Traducción de Enrique Martínez Paz, Madrid: Editorial Reus S.A., pp. 231 a 248.

18 PERELMAN, Chaim (1979). La lógica jurídica y la nueva retórica, Madrid: Editorial Civitas.
} 
proporcional a la especificidad de sus términos, de esta forma las normas más generales tardan muchos años en modificarse o ser derogadas.

La misma Constitución reconoce que las leyes deben ser expedidas por la generalidad de las cosas y no por la diferencia de personas, el ejemplo del "perro doméstico de Perelman" baste como demostración. De otro lado, tampoco puede ser desconocido que la moral ha migrado hacia el interno, como lo reconocen Atienza o Habermas ${ }^{19}$, y más que eso que el principio pro hominem sea un paradigma constitucional.

Una relectura a Kant nos obliga a redefinir el imperativo categórico y sus cuatro formulaciones: a) Actúa siempre de tal manera que la máxima o el fin de tus actos pueda convertirse en principio de legislación universal; b) Actúa de tal forma como si la máxima de tu conducta debiera llegar a ser por medio de tu voluntad una ley natural general; c) Actúa siempre de tal modo que no trates la naturaleza humana, ni en ti ni en los demás, como un medio, sino como un fin en sí mismo; y d) No realices ninguna conducta con base a otra máxima, más que con la que pueda existir la posibilidad que pueda llegar a ser una ley general ${ }^{20}$. Es decir, no como reglas de derecho en sí mismas, sino como normas principio, es decir, condiciones de existencia para que una regla de derecho pueda ser tal y aplicarla al caso concreto, o si se prefiere en palabras de Dworkin criterios de validez o mejor las condiciones de optimización en términos de Alexy.

Por lo tanto, el imperativo categórico nos exige mirar al Derecho como el condicionante necesario de la paz y la felicidad humana, siempre que funcione y se comporte como tal. Prefiriendo interpretaciones o aplicaciones que optimicen el ejercicio de la libertad, con fines humanistas o apreciables, descartando las posiciones que impongan condiciones formalistas, odiosas, maléficas o perversas, bajo la textura jurídica en cada caso concreto. Por supuesto, ello supone dejar de lado la postura positivista de un derecho "independiente de la moral", hacia un derecho moralizado, en el cual las Constituciones y los Tratados sobre Derechos Humanos reconozcan una "moral universal" entendida como el mínimo común irrenunciable, no tanto la cultura idiosincrática grupal o las condiciones de buen humano que por cierto varían de grupo a grupo, sino principios de justicia ineludibles para la libertad,

19 ANGULO LÓPEZ, Geofredo (2014) La ductilidad como núcleo esencial del derecho: La reforma al Artículo $1^{\circ}$ de la Constitución Mexicana, en Revista de estudios Jurídicos No. 14/2014 (Segunda época) ISSN 2340-5066, España: Universidad de Jaén, pp. 3-6.

20 KANT, Immanuel. (1974) Grundlegung zur Metaphysik der Sitten, Frankfurt/Main: Suhrkamp, p. $51-82$. 
al estilo de John Rawls "bajo el velo de la ignorancia, si un Parlamento ideal tuviera que decidir sobre leyes generales, si bien no sabremos estaremos seguros si se aprobarán todas las propuestas, podemos afirmar sin temor a error, que definitivamente las violentas, odiosas y discriminaras no se aprobarán, pues ninguno sabría si éstas les van a afectar" 21 .

\section{La casuística peruana}

El Perú y concretamente el constitucionalismo y los Derechos Humanos exhiben varios casos de ductilidad, de modo expreso la Sentencia del Tribunal Constitucional STC 1776-2004-AA/TC-LIMA, Caso Víctor Augusto Morales Medina, del 26 de enero de 2007, en que resolviendo un caso de libre desafiliación del sistema privado de pensiones en el momento que no existía legalmente tal posibilidad, declara Fundada tal posibilidad, precisamente utilizando a los efectos un derecho a probar entendido de manera dúctil, apartándose del formalismo del onus probandi del artículo $196^{\circ}$ del Código Procesal Civil y reconociendo la posibilidad de la carga probatoria dinámica, como aparece en el fundamento 50.b.

"Se ha señalado prima facie que la carga de probar corresponde a quien afirma hechos que configuran su pretensión, o a quien los contradice alegando nuevos hechos, según lo presenta el artículo $196^{\circ}$ del Código Procesal Civil. Frente a ello, la carga probatoria dinámica significa un apartamiento de los cánones regulares de la distribución de la carga de la prueba cuando esta arroja consecuencias manifiestamente disvaliosas para el propósito del proceso o procedimiento, por lo que es necesario plantear nuevas reglas de reparto de la imposición probatoria, haciendo recaer el onus probandi sobre la parte que está en mejores condiciones profesionales, técnicas o fácticas para producir la prueba respectiva.

En el caso de la falta de información para una afiliación, este precepto no puede ser adecuado, pues reparándose en la naturaleza de los hechos a probar, se puede llegar a pensar en la remisión a un subjetivismo de la SBS, tal como lo reconocía casi explícitamente la nulidad de afiliaciones. Conviene ahora desvirtuar la validez de la 'prueba diabólica' que puede llegar a ser la probanza de que el afiliado no fue informado de forma conveniente.

Un medio probatorio produce certeza en el juez respecto de los puntos controvertidos con el fin de fundamentar sus decisiones. Y sobre ello hay que insistir en el caso del retorno al SNP por falta de información correcta sobre el SPP

21 RAWLS, John. La teoría de la justicia, 6ta. Reimpresión, México: Fondo de Cultura Económica, 2006. 
y sobre el futuro del SNP, máxime si tal figura se justifica precisamente con la asimetría informativa y con la firma de un contrato de adhesión.

La doctrina de las cargas probatorias dinámicas interviene para responder a una concepción de un derecho dúctil y una concepción más dinámica del devenir del proceso, tal como amerita el supuesto planteado. Así, no correspondería al demandante la carga de la prueba del hecho (de indole negativo) sino que el demandado tendría la carga de probar el hecho positivo. Cabe recordar que la prueba dinámica no es ajena a nuestro ordenamiento. Por ejemplo, se han utilizado en los siguientes supuestos: violación de derechos humanos (párrafo 70 de la sentencia del caso Paniagua Morales y otros, párrafo 65 de la sentencia del caso Durand y Ugarte y párrafo 63 de la sentencia del Caso Castillo Petruzzi, todas ellas de la Corte Interamericana de Derechos Humanos), cumplimiento de condiciones de los trabajadores (artículo $27^{\circ}$ de la Ley Procesal del Trabajo, Ley N. ${ }^{\circ}$ 26636) e impugnación de pago de tasa en tributación municipal (sentencias recaídas en el Expediente $N^{\circ}$ 0041-2004-AI/TC y en el Expediente 0053-2004AI/TC). Asimismo, en el ámbito de protección del usuario, y basándose en la asimetría de información, se ha permitido la variación de la carga de la prueba, buscándose proteger al consumidor de la imposibilidad de probar que fue engañado o que recibió información insuficiente (punto 2 la Resolución $N^{o} 102-$ 97-TDC-INDECOPI).

En el caso concreto del retorno, serán el Estado y la AFP los que deberán probar que informaron correctamente a cada grupo de afiliados que se adscribieron al SPP. En el procedimiento será la AFP la que establecerá, en primer lugar, si informó bien o mal, aunque es muy dificil que ella misma acepte tal responsabilidad. Por su parte, la SBS, con mayor grado de independencia, por no participar del sistema pensionario directamente, sino únicamente a través de la supervisión, sí estará en capacidad de determinar la falta de quien corresponda. Pero por la naturaleza de sus funciones no estará en capacidad de fijar el grado de información existente en el ámbito pensionario, toda vez que la existencia de una información asimétrica requiere ser probada y analizada por un organismo especializado sobre la materia."

Otras referencias expresas aparecen pero en los votos singulares del Magistrado César Álvarez Miranda fundamentando su voto en discordia en la Sentencia STC del Expediente No. 01711-2014-PHC/TC-LIMA, Caso Víctor Polay Campos, Peter Cárdenas Schulte, Óscar Ramírez Durand y Miguel Rincón Rincón, del 08 de abril de 2014 y del Magistrado César Landa Arroyo fundamentando su voto a favor en la Sentencia STC del Expediente No. 050272008-PC/TC-LIMA, Caso Asociación Aurora Vivar, el Centro de la Mujer Peruana Flora Tristán, la Asociación Demus Estudio para la Defensa de los 
Derechos de la Mujer, la Asociación Movimiento El Pozo, el Movimiento Manuela Ramos, doña Elva María Jara Salas y doña Betsey Cecilia Valdivia López, del 30 de junio de 2010.

Otras aplicaciones indirectas aparecen en varias sentencias, como la Sentencia STC 2488-2002-HC/TC - PIURA, Caso Genaro Villegas Namuche que protege el derecho a la verdad como Derecho Humano, del 18 de marzo de 2004, que en su fundamentos 8 a 20 justifican la existencia real del Derecho a la verdad aunque no tenga reconocimiento expreso en la Carta Fundamental escrita: "el derecho a la verdad, aunque no tiene un reconocimiento expreso en nuestro texto constitucional, es un derecho plenamente protegido, derivado en primer lugar de la obligación estatal de proteger los derechos fundamentales y de la tutela jurisdiccional."

O la misma Constitución de 1993 repudiada por muchos pero finalmente cumplida y exigida como Norma Fundamental, al punto que el mismo Presidente Humala aunque juró por los principios de la Constitución de 1979 exige el tratamiento para su esposa Nadine Heredia o para sus Ministros bajo las reglas de la actual Constitución.

O las Sentencias STC 06546-2006-PA/TC - LAMBAYEQUE, Caso César Augusto Zúñiga López, del 7 de noviembre de 2007, Fundamentos Jurídicos 5 y 6 , que reconoce el derecho al agua potable, que no se encuentra dentro del catálogo de Derechos escritos en la Constitución Política peruana de 1993.

"En el caso específico del derecho al agua potable,... aunque dicho atributo no se encuentra considerado a nivel positivo, existen no obstante una serie de razones que justifican su consideración o reconocimiento en calidad de derecho fundamental. Asumir dicha premisa supone, sin embargo, perfilar su individualización dentro del contexto que ofrecen algunas de las perspectivas anteriormente enunciadas. A tales efectos y en la medida en que no existe norma expresa que contenga dicho reconocimiento a nivel interno y que a nivel internacional aún se encuentran pendientes de desarrollo muchos de los ámbitos que comprendería dicho atributo, se hace permisible acudir, para tal efecto, principalmente a la opción valorativa o principialista y la cláusula de los derechos implícitos que le permite servir de referente. Así las cosas, la utilización de la fórmula de individualización antes descrita posibilitaría legitimar la existencia de un derecho al agua potable en calidad de atributo fundamental no enumerado. Su reconocimiento se encontraría ligado directamente a valores tan importantes como la dignidad del ser humano y el Estado Social y Democrático de Derecho.

El derecho al agua potable, a la luz del contexto descrito, supondría, primariamente, un derecho de naturaleza positiva o prestacional, cuya 
concretización correspondería promover fundamentalmente al Estado. Su condición de recurso natural esencial lo convierte en un elemento básico para el mantenimiento y desarrollo no solo de la existencia y la calidad de vida del ser humano, sino de otros derechos tan elementales como la salud, el trabajo y el medio ambiente, resultando prácticamente imposible imaginar que sin la presencia del líquido elemento, el individuo pueda ver satisfechas sus necesidades elementales y aun aquellas otras que, sin serlo, permiten la mejora y aprovechamiento de sus condiciones de existencia."

Mismo criterio y con idénticas frases aparece en la Sentencia en el Expediente STC 06534-2006-PA/TC - LIMA, Caso Santos Eresmina Távara Ceferino, del 15 de noviembre de 2007, cuyos fundamento 17 y 18, contienen la misma redacción.

Finalmente, resulta indispensable citar que la jurisprudencia de la Corte Interamericana de Derechos Humanos ha establecido de un tiempo a esta parte, un derrotero de salvaguarda de los Derechos Humanos como obligación ineludible de todos los actores públicos, no solo los jueces, aunque especialmente ellos, que solo sería posible admitiendo la ductilidad de los Derechos Humanos. El Perú ya ha tenido un pronunciamiento de ida y vuelta, al respecto, en lo que concierne al denominado "control difuso administrativo", partiendo de la Sentencia del caso Ramón Hernando Salazar Yarleque en el Expediente No. 3741-2004-AA/TC-LIMA, del 14 de noviembre de 2005, en que fijó como precedente vinculante que los órganos colegiados y tribunales administrativos estaban en la obligación de control de la constitucionalidad de las leyes y reglamentos que les corresponde aplicar. Sin embargo, posteriormente dicta la Sentencia en el caso Consorcio Requena en el Expediente No. 04293-2012-PA/TC-LORETO, del 18 de marzo de 2014, en que derogando el precedente Salazar Yarleque en lo que respecta al control constitucional, dictó el precedente indicando que el exclusivo contralor de la constitucionalidad es el Tribunal Constitucional, tarea en que - para el caso particular - le acompañan los jueces que pueden pronunciar un interdicto constitucional no aplicando una ley por motivos constitucionales, pero ningún otro órgano del Estado, eliminando la potencia conferida en el precedente vinculante derogado de 2005, por este nuevo precedente vinculante. Por cierto, estos vaivenes demuestran que la tesis de la ductilidad todavía no es admitida por completo ni para todas las áreas del Derecho peruano.

La Corte Interamericana de Derechos Humanos (o la Corte), por el contrario ha extendido el vigor de ductilidad a todas las esferas públicas, exigiendo obligatoriamente el control de convencionalidad por todos los que ejercen 
cargos públicos. Y aunque no ha sido un criterio impostado plenamente desde el comienzo, en cambio podemos afirmar un "in crescendo" constante que comenzó hace ya varios años y que se ha ido consolidando con el paso del tiempo, a pesar de las diferente composición de los Ministros que han integrado la Corte.

El itinerario del Corte es identificable fácilmente, empezando por la Resolución No. 166 del Caso Almodacid Arellano Versus la República de Chile, Sentencia del 16 de setiembre de 2006, emitida por la Corte Interamericana de Derechos Humanos. Fundamento 124. En la cual establece la premisa fundamental del control de convencionalidad, obligando tal ejercicio a todos los jueces bajo la jurisdicción de la Corte, al manifestar:

La Corte es consciente que los jueces y tribunales internos están sujetos al imperio de la ley y, por ello, están obligados a aplicar las disposiciones vigentes en el ordenamiento jurídico. Pero cuando un Estado ha ratificado un tratado internacional como la Convención Americana, sus jueces, como parte del aparato del Estado, también están sometidos a ella, lo que les obliga a velar porque los efectos de las disposiciones de la Convención no se vean mermadas por la aplicación de leyes contrarias a su objeto y fin, y que desde un inicio carecen de efectos jurídicos. En otras palabras, el Poder Judicial debe ejercer una especie de "control de convencionalidad" entre las normas jurídicas internas que aplican en los casos concretos y la Convención Americana sobre Derechos Humanos. En esta tarea, el Poder Judicial debe tener en cuenta no solamente el tratado, sino también la interpretación que del mismo ha hecho la Corte Interamericana, intérprete última de la Convención Americana."

Luego vendría una secuencia de resoluciones que amplifican esta obligación a los jueces a quienes les exige a "velar porque el efecto útil de la Convención no se vea mermado o anulado por la aplicación de leyes contrarias a sus disposiciones, objeto y fin." En la Resolución No. 170 del Caso Trabajadores cesados del Congreso (Aguado Alfaro y otros) Versus la República de Perú, Sentencia del 24 de noviembre de 2006, emitida por la Corte Interamericana de Derechos Humanos. Fundamento 128. Más adelante, transfiere esa misma obligación a "todos los órganos vinculados a la administración de justicia en todos los niveles"; en la Resolución No. 233 del Caso Gelman Versus la República de Uruguay, Sentencia del 24 de febrero de 2011, emitida por la Corte Interamericana de Derechos Humanos. Fundamento 193. En seguida a "todos sus órganos, incluido el poder judicial" como lo afirma en la Resolución No. 265 del Caso Gudiel Álvarez y otros ("Diario Militar") Versus la República de Guatemala, Sentencia 
del 20 de noviembre de 2012, emitida por la Corte Interamericana de Derechos Humanos. Fundamento 330.

Y más recientemente, con la mayor amplitud, exige expresamente "la obligación de ejercer un control de convencionalidad entre las normas internas y la Convención Americana le compete a todos los órganos del Estado, incluidos sus jueces y demás órganos vinculados a la administración de justicia en todos los niveles" en la Resolución No. 288 del Caso Liakat Ali Alibux Vs Suriname, Sentencia del 30 de enero de 2014, emitida por la Corte Interamericana de Derechos Humanos. Fundamento 124, obligación que en el Fundamento 151, establece debe ser " ex officio". Esta disposición la vuelve a afirmar en la Resolución No. 294 del Caso Personas dominicanas y haitianas expulsadas Versus la República Dominicana, Sentencia del 28 de agosto de 2014, emitida por la Corte Interamericana de Derechos Humanos. Fundamento 310.

Este derrotero, a pesar de su polémica implicancia, como lo ha sido - según dijimos - para el mismo Tribunal Constitucional peruano, que no ve siquiera posible que los demás órganos que no sean el Poder Judicial o el Tribunal Constitucional, puedan dictar decisiones de control de la constitucionalidad. La Corte en distinta opinión en cambio señala que la obligación del respeto y valía de los Derechos Humanos, es una obligación de los estados no solo en acciones negativas (no violar dichos derechos) sino en acciones positivas (ser responsable que otros, incluyendo sus propios ciudadanos no los violen). Este alcance internacional, es una corriente, que en mi opinión ya es inevitable, por lo que cada vez cobra mayor sentido, que los Derechos Humanos sean vistos como razones superiores de convivencia armónica y ello supone verlos inevitablemente como dúctiles, para una sociedad tan plural y diversa como lo es la nuestra.

\section{Conclusión}

Entender a los Derechos Humanos como dúctiles supone en principio aceptar que el hecho, que estén escritos es secundario y relativo. Que se legislan porque son Derechos y no al revés, por lo tanto pueden aparecer de diversas fuentes, e incluso reconocerse no escritos. En segundo lugar, que solo una interpretación dúctil del derecho y concretamente de los Derechos Humanos permite su aplicación en igualdad a todos, sin menoscabo de las identidades y diversidades, ya que un contenido dinámico permite la convergencia de diferentes características. Y finalmente que esta condición de ductilidad permite la consolidación de la humanidad, como un valor ético superior y 
anterior, por encima de las fronteras y de los regionalismos, que muchas veces son el germen de la guerra, la violencia y la discriminación. A.M.D.G.

\section{Bibliografia}

AGUSTÍN, San. La ciudad de Dios, CLXIX, Madrid: BAC. (1957) Del libre albedrío, I - ML, Madrid: BAC, 1956.

ALEXY, Robert. Teoría de los derechos fundamentales, Madrid: Centro de Estudios Políticos y Constitucionales, 2002.

ANGULO LÓPEZ, Geofredo. "La ductilidad como núcleo esencial del derecho: La reforma al Artículo $1^{\circ}$ de la Constitución Mexicana", en Revista de estudios Jurídicos No. 14/2014 (Segunda época) ISSN 2340-5066, España: Universidad de Jaén, 2014.

ARISTÓTELES. Constitución de Atenas. Edición, traducción y notas con estudio preliminar por Antonio Tovar (reimp. 1970). Madrid: Instituto de Estudios Políticos (en la actualidad, Centro de Estudios Políticos y Constitucionales), 1948

BIDART CAMPOS, Germán. Teoría general de los Derechos Humanos, México D.F.: Universidad Nacional Autónoma de México, 1989.

Habermas, Jürgen. La teoría de la acción comunicativa, Madrid: Taurus; (2002) Verdad y justificación, Madrid: Trotta, 1987.

HESIODO. Los trabajos y los días, Ecuador: Omega, 2003.

JIMÉNEZ SÁNCHEZ, Joaquín. La fundamentación de los derechos humanos. Los derechos humanos como derechos morales, España - Granada: Cuadernos Electrónicos de Filosofía del Derecho. núm. 1, UGR, 1998.

KANT, Immanuel. (1974). Grundlegung zur Metaphysik der Sitten, Frankfurt/Main: Suhrkamp.

LANDA ARROYO, César. La aplicación de los Tratados internacionales en el Derecho interno y la Corte Interamericana de Derechos Humanos, México DF: UNAM, 2002.

LARENZ, Karl. Metodología de la Ciencia del Derecho, Barcelona: Editorial Ariel S.A., 1994.

LeIBHOLZ, Gerhard. Igualdad ante la Ley, Madrid: Librería Pérez Galdón - El Galeón, 1963.

LUJÁN TUPEZ, Manuel Estuardo. “El certiorari decissum”, en Revista Jurídica del Colegio de Abogados de La Libertad, No. 147, Trujillo: CALL, 2014.

PERELMAN, Chaim. La lógica jurídica y la nueva retórica, Madrid: Editorial Civitas, 1979.

RAWLS, John. La teoría de la justicia, 6ta. Reimpresión, México: Fondo de Cultura Económica, 2006. 
RousseAU, Jean Jacques. Du Contrat social; ou, principes du droit politique [El contrato social; o los principios del derecho político] (en francés). Amsterdam: Marc Michel Rey. Traducción y edición, www.elaleph.com, 1762; consultado el 05 de febrero de 2016, página web que aparece http://www.enxarxa.com/biblioteca/ROUSSEAU\%20El\%20Contrato\%2 OSocial.pdf

STAMMLER, Rudolf. Teoría del Derecho justo. Traducción de Enrique Martínez Paz, Madrid: Editorial Reus S.A, 1970.

Schmitt, Carl. El nomos de la tierra, en el Derecho de Gentes del Ius Publicum Europeum, Granada: Comares, 2003.

TOCQUEVILLE, Alexis de. La democracia en América, Trad. de Dolores Sánchez de Aleu. Madrid: Alianza Editorial, 2002.

ZAGREBELSKY, Gustavo. El derecho dúctil. Madrid: Editorial Trotta, 4a . Edición, 2002. 